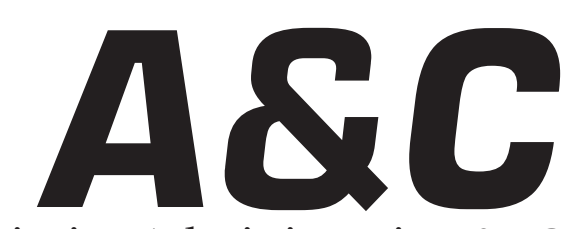

Revista de Direito Administrativo \& Constitucional

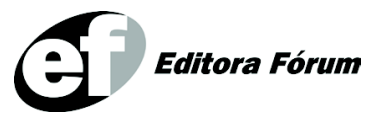

ISSN $1516-3210$ 


\section{A\&C REVISTA DE DIREITO ADMINISTRATIVO E CONSTITUCIONAL}

IPDA

Instituto Paranaense

de Direito Administrativo

Direção Geral

Romeu Felipe Bacellar Filho

Direção Editorial

Paulo Roberto Ferreira Motta

Direção Executiva

Emerson Gabardo

Conselho de Redação

Edgar Chiuratto Guimarães

Adriana da Costa Ricardo Schier

Célio Heitor Guimarães

\section{Conselho Editorial}

Adilson Abreu Dallari

Alice Gonzáles Borges

Carlos Ari Sundfeld

Carlos Ayres Britto

Carlos Delpiazzo

Cármen Lúcia Antunes Rocha

Celso Antônio Bandeira de Mello

Clèmerson Merlin Clève

Clóvis Beznos

Enrique Silva Cimma

Eros Roberto Grau

Fabrício Motta

Guilhermo Andrés Muñoz (in memoriam)

Jaime Rodríguez-Arana Muñoz

Jorge Luís Salomoni

José Carlos Abraão
José Eduardo Martins Cardoso
José Luís Said
José Mario Serrate Paz
Juan Pablo Cajarville Peruffo
Juarez Freitas
Julio Rodolfo Comadira
Luís Enrique Chase Plate
Lúcia Valle Figueiredo
Manoel de Oliveira Franco Sobrinho
(in memoriam)
Marçal Justen Filho
Marcelo Figueiredo
Márcio Cammarosano
Maria Cristina Cesar de Oliveira

Nelson Figueiredo

Odilon Borges Junior

Pascual Caiella

Paulo Eduardo Garrido Modesto

Paulo Henrique Blasi

Paulo Neves de Carvalho (in memoriam)

Paulo Ricardo Schier

Pedro Paulo de Almeida Dutra

Regina Maria Macedo Nery Ferrari

Rogério Gesta Leal

Rolando Pantoja Bauzá

Sérgio Ferraz

Valmir Pontes Filho

Yara Stropa

Weida Zancaner

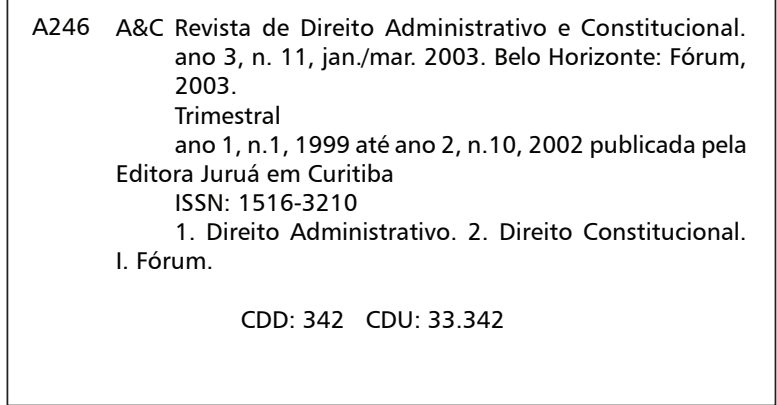

(c) Editora Fórum Ltda. 2006

Todos os direitos reservados. É proibida a reprodução total ou parcial, de qualquer forma ou por qualquer meio eletrônico ou mecânico, inclusive através de processos xerográficos, de fotocópias ou de gravação, sem permissão por escrito do possuidor dos direitos de cópias (Lei $n^{\circ}$ 9.610, de 19.02.1998).

\section{Editora Fórum Ltda}

Av. Afonso Pena, 2770 - 15\%16ªndar - Funcionários

CEP 30130-007 - Belo Horizonte/MG - Brasil

Tel.: 08007043737

Internet: www.editoraforum.com.br

e-mail: editoraforum@editoraforum.com.br
Editor responsável: Luís Cláudio Rodrigues Ferreira Projeto gráfico e diagramação: Luis Alberto Pimenta Revisora: Olga M. A. Sousa

Pesquisa jurídica: Fátima Ribeiro - OAB/MG 74868

Bibliotecária: Alessandra Rodrigues da Silva CRB 2778/MG 6 ${ }^{\text {a Região }}$

Os conceitos e opiniões expressas nos trabalhos assinados são de responsabilidade exclusiva de seus autores.

Impressa no Brasil / Printed in Brazil

Distribuída em todo Território Nacional 


\title{
O custo dos direitos prestacionais
}

\author{
Cláudia Honório \\ Advogada. Bacharel em Direito pela Universidade Federal do Paraná. Especializanda em Direito
} Constitucional pela UniBrasil

Sumário: Introdução - 1 Os direitos prestacionais - 2 A reserva do possível - 3 Frente à escassez, uma solução - $4 \mathrm{O}$ papel do judiciário - 5 A ponderação de interesses - 6 Instrumental novo - Conclusão - Referências

Palavras-chave: Direito prestacional. Direitos sociais. Recursos públicos. Reserva do possível.

\section{Introdução}

Um direito pode estar assegurado na Constituição e na legislação ordinária e mesmo assim sua efetivação ser difícil. Trata-se de norma que garante direito prestacional positivo - que se refere a um agir do Estado no campo material, na definição de Gustavo Amaral. ${ }^{1}$ Um dos principais óbices à sindicalização desses direitos — como são os direitos à saúde, à moradia, à educação, à assistência social e ao salário mínimo, por exemplo é a falta de recursos públicos. Será esse argumento válido e forte o bastante para restringir direitos? É o que tentaremos esclarecer nas linhas a seguir.

\section{Os direitos prestacionais}

Na classificação de Robert Alexy, o direito de exigir uma prestação material do Estado é prestacional em sentido estrito (ou direito social fundamental).

Los derechos a prestaciones en sentido estricto son derechos del individuo frente al Estado a algo que - si el individuo poseyera medios financieros suficientes y si encontrase en el mercado una oferta suficiente - podría obtenerlo también de particulares. Cuando se habla de derechos sociales fundamentales, por ejemplo, del derecho a la previsión, al trabajo, la vivienda y la educación, se hace primariamente referencia a derechos a prestaciones en sentido estricto. ${ }^{2}$

Os direitos sociais representam a incumbência do Estado de colocar à disposição do cidadão meios materiais necessários à existência digna. Brilhante Celso de Albuquerque Mello, ${ }^{3}$ ao dizer que não podemos abandonar o homem em uma política neo-darwinista, em que apenas os

1 AMARAL, 2001a.

2 ALEXY, 1997, p. 482.

A \& C R. de Dir. Administrativo e Constitucional, Belo Horizonte, ano 6, n. 25, p. 145-159, jul./set. 2006 
que têm condições de pagar pela sua manutenção têm chance de viver.

Contudo, apesar da garantia do texto legal, existe, no dizer de Andreas Krell, um "livre espaço de conformação" desses direitos: "A apreciação dos fatores econômicos para uma tomada de decisão quanto às possibilidades e aos meios de efetivação desses direitos cabe principalmente aos governos e parlamentos." ${ }^{4}$ Ingo Sarlet reconhece que a simples vigência não garante a efetividade da norma; a positivação não fornece o instrumental suficiente para a concretização.

\section{A reserva do possível}

De fato a efetividade relaciona-se a aspectos externos à mera existência da norma, como a suficiência de meios financeiros para a realização do conteúdo normativo. É nesse sentido que se remete ao princípio da reserva do possível, explicado por Ana Paula de Barcellos:

A expressão reserva do possível procura identificar o fenômeno econômico da limitação dos recursos disponíveis diante das necessidades quase sempre infinitas a serem por eles supridas. No que importa ao estudo aqui empreendido, a reserva do possível significa que, para além das discussões jurídicas sobre o que se pode exigir judicialmente do Estado - e em última análise da sociedade, já que é esta que o sustenta - é importante lembrar que há um limite de possibilidades materiais para esses direitos. Em suma: pouco adiantará, do ponto de vista prático, a previsão normativa ou a refinada técnica hermenêutica se absolutamente não houver dinheiro para custear a despesa gerada por determinado direito subjetivo. ${ }^{5}$

Com base na escassez de recursos, é bastante comum no Brasil a falta de efetividade dada aos direitos prestacionais. Andréas Krell explica muito bem o que significava a argumentação da reserva do possível quando surgiu, no direito alemão:

Segundo o Tribunal Constitucional Federal da Alemanha, esses direitos a prestações positivas (Teilhaberechte) "estão sujeitos à reserva do possível no sentido daquilo que o indivíduo, de maneira racional, pode esperar da sociedade”. Essa teoria impossibilita exigências acima de um certo limite básico social; a Corte recusou a tese de que o Estado seria obrigado a criar a quantidade suficiente de vagas nas universidades públicas para atender a todos os candidatos. Alguns autores brasileiros acataram a argumentação da "reserva do possível" negando de maneira categórica a competência dos juízes ("não legitimados pelo voto") a dispor sobre medidas de políticas sociais que exigem gastos orçamentários. ${ }^{6}$

\footnotetext{
${ }^{3}$ MELLO, 2001.

${ }^{4}$ KRELL, 2002, p. 22.

${ }^{5}$ BARCELLOS, 2002, p. 236-237.
}

A \& C R. de Dir. Administrativo e Constitucional, Belo Horizonte, ano 6, n. 25, p. 145-159, jul./set. 2006 
A transmutação da teoria da reserva do possível para o Brasil foi equivocada. "Devemos nos lembrar também que os integrantes do sistema jurídico alemão não desenvolveram seus posicionamentos para com os direitos sociais num Estado de permanente crise social e milhões de cidadãos socialmente excluídos." Defende Alexy que é justamente em tempos de crise econômica que "parece indispensable uma protección iusfundamental de las posiciones sociales, por más mínima que ella sea."

A reserva do possível restringe a sindicalização de prestações estatais positivas. Na dimensão fática, significa proteger o princípio igualitário: "Certas prestações, uma vez determinadas pelo Judiciário em favor do postulante que ajuizasse ação neste sentido, poderiam canalizar tal aporte de recursos que se tornaria impossível estendê-las a outras pessoas, [...]." A Amposição de escolhas dramáticas traz a necessidade de definir prioridades no atendimento dos direitos, o que será feito por autoridades eleitas. Na dimensão jurídica, a reserva do possível evita a interferência do Judiciário no orçamento.

Observa José Eduardo Faria: “[...] as decisões políticas tornam-se condicionadas por equilíbrios macro-econômicos que representam, mais do que um mero indicador, um verdadeiro princípio normativo responsável pela fixação de rigorosos limites às intervenções reguladoras dos Estados nacionais." ${ }^{10}$

Também considerando a ordem econômica, José Joaquim Gomes Canotilho $^{11}$ afirma que o volume de recursos públicos é um limite fático à efetivação dos direitos a prestações positivas. Certo é que ao falarmos em implementação de direitos prestacionais, há que se atentar para os recursos públicos. Isso não significa, para Gustavo Amaral, que os economicistas operarão o direito, por meio da relação custo-benefício.

Levar o custo dos direitos em conta é então se portar como um administrador prudente, que se indaga sobre como alocar inteligentemente recursos limitados, levando em conta o amplo espectro de bens e utilidades públicas. Os direitos assegurados em lei têm "custos de oportunidade"; quando um direito é tornado efetivo, outros bens valiosos, inclusive direitos, são postos à margem, pois os recursos consumidos para dar eficácia àquele direito são escassos. ${ }^{12}$

\footnotetext{
6 KRELL, 2002, p. 52.

KRELL, 2002, p.108.

8 ALEXY, 1997, p. 496.

9 GOUVÊA, 2003, p. 19.

10 FARIA, 1998, p. 142

${ }^{11}$ Em CANOTILHO; MOREIRA, 1991.
}

A \& C R. de Dir. Administrativo e Constitucional, Belo Horizonte, ano 6, n. 25, p. 145-159, jul./set. 2006 
Ainda Amaral:

Pretender que as prestações positivas possam, sempre e sempre, ser reivindicáveis, pouco importando as conseqüências financeiras e eventuais impossibilidades do Erário é divorciar tais pretensões de qualquer fundamento de justiça, seja porque a falta de recursos provocará discriminações arbitrárias sobre quem receberá a utilidade concreta e quem não receberá [...] e, ainda, desequilíbrio entre as pretensões voltadas para abstenções arrecadatórias e, ainda, com anseios difusos, voltados para um estado de equilíbrio social, incompatível com a total desestabilização das finanças públicas. ${ }^{13}$

A escassez é própria da essência das coisas. Um bem é escasso quando não há o suficiente para satisfazer a todos. Não sendo possível atender todos, o que ou quem atender? Há uma gama de métodos para decidir a alocação de recursos. Isso se deve à dificuldade da tarefa moral de negar a alguém um recurso vital, motivo pelo qual se procura um critério neutro ou mesmo escolher nada escolher. Conclui Amaral que as decisões tendem a ser políticas e locais.

Político e local é o orçamento, primeira forma de alocar recursos escassos. O orçamento público, para Ricardo Lobo Torres, é “o balanço das escolhas dramáticas por políticas públicas em um universo fechado de recursos financeiros escassos e limitados." 14 A composição dos orçamentos públicos e a decisão sobre a aplicação dos recursos são tarefas do Legislativo e do Executivo.

Contudo, a alegação de insuficiência orçamentária para desobrigar a implantação de programa social não cabe frente ao dever estatal de observar o mandamento constitucional. Diante da escassez de recursos, deve-se agir com responsabilidade. Sarlet sublinha que "[...] o reconhecimento e efetivação dos direitos sociais, ainda que em patamar mínimo, voltado à manutenção de um nível existencial digno, transforma-se em meta indispensável a qualquer ordem estatal que tenha a pretensão de ostentar o título de legítima e, por via de conseqüência, genuinamente democrática." 15

Sergio Fernando Moro lança mão do princípio da razoabilidade: a prioridade é economizar o dinheiro público ou propiciar vida digna aos milhões de brasileiros? "Não se afigura razoável restringir os gastos públicos exatamente com aqueles mais vulneráveis. Ao contrário, o que se

\footnotetext{
12 HOLMES; SUNSTEIN, 1999, p. 223-224. Tradução livre de Gustavo Amaral.

${ }_{13}$ AMARAL, 2001b, p. 117.

14 TORRES, 2001 a, p. 278.
}

A \& C R. de Dir. Administrativo e Constitucional, Belo Horizonte, ano 6, n. 25, p. 145-159, jul./set. 2006 
reclama é a melhor focalização dos gastos públicos, inclusive dos de cunho social, com os mais necessitados." ${ }^{16} \mathrm{O}$ autor sugere a reorganização dos gastos públicos, enfatizando o panorama social.

Luis Roberto Barroso lembra a importância da cidadania participativa para a efetividade da Constituição. Na medida em que se administram recursos escassos na atuação dos poderes estatais, a pressão da sociedade civil se torna decisiva na eleição das prioridades orçamentárias.

A consideração dos direitos como poderes individuais derivados da qualidade de membro de uma comunidade política, e como investimentos seletivos de recursos coletivos escassos, com o objetivo de alcançar fins comuns e resolver problemas considerados como urgentes, é uma visão realista, como defende Gustavo Amaral, com base em Holmes e Sunstein:

No right whose enforcement presupposes a selective expenditure of taxpayer contributions can, at the end of the day, be protected unilaterally by the judiciary without regard to budgetary consequences for which other branches of government bear the ultimate responsibility. [...] Public finances is an ethical science because it force us to provide a public accounting for the sacrifices that we, as a community, decide to make, to explain what we are willing to relinquish in pursuit of our more important aims. ${ }^{17}$

Sarlet apresenta um paradoxo: os juízes não se negam a conceder uma ordem de habeas corpus com base no argumento de que o Estado não dispõe de recursos suficientes para garantir o direito à liberdade. Entrementes, esse é o lugar comum quando se trata dos direitos prestacionais. Silvio Dobrowolski comprova: "Enquanto instrumentos processuais refinados tutelam a propriedade e a liberdade - principalmente em favor dos estratos sociais mais aquinhoados - problemas de alimentação, moradia, saúde e educação dos menos favorecidos restam sem solução, descumpridas as promessas consignadas nos direitos sociais." 18

Quando usada para retirar a efetividade dos direitos sociais, a reserva do possível não se sustenta, sendo puro manejo político. Com razão Andreas Krell afirma que se os direitos sociais dependessem do fato de estarem cheios os cofres públicos, eles nunca teriam efetividade. Eles dependem, isso sim, de vontade política. Não estamos falando de esmola ou caridade, mas de direitos fundamentais. Não queremos o impossível;

\footnotetext{
15 SARLET, 2002, p. 189.

${ }^{16}$ MORO, 2003, p. 157.

${ }^{17}$ HOLMES; SUNSTEIN, 1999, p. 97.
}

A \& C R. de Dir. Administrativo e Constitucional, Belo Horizonte, ano 6, n. 25, p. 145-159, jul./set. 2006 
queremos apenas que os direitos sociais sejam levados a sério.

A falta de vontade de Constituição, vontade esta tão preconizada por Konrad Hesse, revela-se, por exemplo, com a seguinte informação: "Em Santo Antônio Lopes, no Maranhão, os R $\$ 386$ mil repassados pelos Ministérios do Meio Ambiente e da Integração Nacional para construção de 13 açudes foram integralmente gastos enquanto as obras, apenas iniciadas." ${ }^{19}$ Em um país que assiste diariamente a notícias de malas com milhões de reais e gordas verbas para políticos e mil e tantos de partidos, cabe alegar seriamente a reserva do possível?

\section{Frente à escassez, uma solução}

Quando mais de um direito essencial demanda o emprego de recursos públicos escassos, sendo que esses direitos não podem ser simultaneamente realizados, qual atender? Nessa situação, surge o que Amaral denomina de escolha dramática. "Será ela (a decisão, a escolha), pois, meramente relativa e circunstancial, muito embora possa significar a vida ou a morte de alguém." ${ }^{20}$ Assim, não basta o direito estar na lei para ter a certeza da sua realização.

Mas quando um direito é essencial? Responde Alexy: "Um interesse ou uma carência é, nesse sentido, fundamental quando sua violação ou não-satisfação significa ou a morte ou sofrimento grave ou toca o núcleo essencial da autonomia. Daqui são compreendidos não só os direitos de defesa liberais clássicos, senão, por exemplo, também direitos sociais que visam ao asseguramento de um mínimo existencial." ${ }^{21}$

Evidente a fundamentalidade do interesse juridicamente protegido pelas normas que garantem saúde, assistência social, salário mínimo, moradia, educação e alimentação, pois sem elas, o cidadão ficará sem alimento, remédio, instrução, abrigo — situações que não condizem com a dignidade e a autonomia inerentes à pessoa.

E para Ricardo Lobo Torres, se houver necessidade, a prestação estatal é obrigatória, independentemente de crise financeira. Nesses casos, adverte o autor, a ação estatal será limitada ao mínimo de bens adequados às necessidades de sobrevivência dos desamparados. Não é função do Estado livrar toda a população de todas as suas necessidades

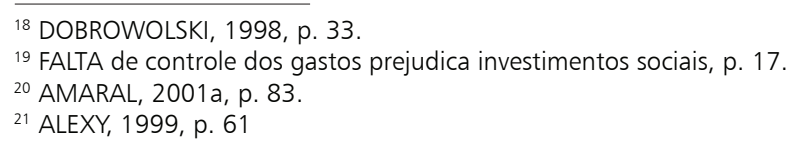

A \& C R. de Dir. Administrativo e Constitucional, Belo Horizonte, ano 6, n. 25, p. 145-159, jul./set. 2006 
materiais. É posição coerente com o cuidado orçamentário e a proteção do mínimo existencial.

Concordamos que deve existir seletividade na concessão das prestações, pois não é possível atender a todos em vista a escassez de recursos. É correto pensar que o Estado não pode ajudar a totalidade de seus cidadãos. Existiria, então, a compreensão de que as prestações devem se limitar aos mais pobres, porquanto o Estado não tem condições de sustentar todos os que precisam, funcionando a limitação como meio de garantir que pelo menos os mais necessitados sejam amparados pelo Poder Público. A opção seria ajudar os extremamente carentes. Contudo, não entendemos ser moralmente aceitável que se deixe o ser humano chegar ao ponto mais sofrível da carência para que seja digno da ajuda estatal.

\section{O papel do judiciário}

A questão a ser analisada, propõe Krell, é quem pode decidir o que fazer frente à escassez de recursos. Para Böckenforde,

Las inevitables decisiones sobre prioridades, sobre el empleo y distribución de los medios financieros estatales disponibles, motivado por la escasez de recursos, pasan de ser una cuestión de discricionalidad política a una cuestión de observancia de los derechos fundamentales, más exactamente: de concurrencia y conflicto de derechos fundamentales; con ello si convierten, formalmente, en una cuestión de interpretación de los derechos fundamentales. Siendo consecuentes, la competencia para adoptar-las se desplaza del Parlamento, o, en su caso, del Gobierno como detentador de la competencia presupuestaria, a los Tribunales, y, en ultima instancia al Tribunal Constitucional Federal. La consecuencia seria una juridificación de las disputas políticas, unida a un desplazamiento da competencia de importantes dimensiones en favor del Tercer poder. ${ }^{22}$

Cabe ao Judiciário o papel ativo na realização dos fins sociais das políticas públicas, corrigindo a prestação dos serviços básicos, se Legislativo e Executivo falharem. O orçamento é lei que vincula, e não mero ato autorizativo; portanto, sua execução pode ser controlada. Segundo Clèmerson Merlin Clève, é perceptível que ao invés de nosso país redistribuir as riquezas, está concentrando-as, e que os gastos com os direitos sociais são ínfimos. Torna-se necessária, nesse contexto, a adoção de um novo plano que adote como prioridade a realização dos direitos

\footnotetext{
${ }^{22}$ AMARAL, 2001a, p. 64.
}

A \& C R. de Dir. Administrativo e Constitucional, Belo Horizonte, ano 6, n. 25, p. 145-159, jul./set. 2006 
fundamentais, e não os interesses do mercado financeiro.

Diante da necessidade de realizar os preceitos do Estado Social Democrático de Direito e da insuficiência de recursos, Gustavo Amaral incumbe ao magistrado a tarefa de

projetar o conteúdo de pretensão positiva em que está investido o particular para, depois, contrastando o teor dessa pretensão com a realidade fática, verificar se há violação potencial. Havendo a violação potencial, cabe ao magistrado, então, questionar as razões dadas pelo Estado para suas escolhas, fazendo a ponderação entre o grau de essencialidade da pretensão e o grau de excepcionalidade da situação concreta, a justificar, ou não, a escolha estatal. ${ }^{23}$

Constatada a essencialidade do direito e a inevitável escassez de recursos, a demanda, em concreto, será regida pela solução dada por Amaral. Por ser mais instrutivo, organizamos a formulação do autor em etapas.

Inicialmente há a exigência, pelo cidadão, de uma atuação positiva material do Estado. Em face do pedido, o Estado entrega a prestação ou justifica a não-entrega. A justificativa será a constatação de que circunstâncias concretas impedem o atendimento a todos os que demandam prestações, o que leva a inevitáveis escolhas dramáticas. O Estado, então, utilizará um critério para determinar o que deve ser atendido; o que não for atendido terá, portanto, razão legítima para sê-lo. Em vista disso, descabida qualquer responsabilização do Estado pela negativa da prestação.

Caso o Estado não entregue a prestação, o cidadão pode recorrer ao Judiciário, o qual fará a ponderação entre essencialidade da prestação e excepcionalidade. Poderá concluir o magistrado que se trata de prestação essencial sem razão para não ser atendida, não se justificando, portanto, a negativa do Estado no atendimento da prestação. O Judiciário, então, poderá conceder a prestação positiva, porque a escolha feita politicamente não se sustenta.

Resumindo, "Caberá ao aplicador ponderar essas duas variáveis (essencialidade e excepcionalidade), de modo que se a essencialidade for maior que a excepcionalidade, a prestação deve ser entregue, caso contrário, a escolha estatal será legítima." ${ }^{24}$ A excepcionalidade, para Amaral, é entendida como a razão para deixar de atender o direito como a falta de recursos. De acordo com esse raciocínio, se a essenciali-

${ }^{23}$ AMARAL, 2001a, p. 208

A \& C R. de Dir. Administrativo e Constitucional, Belo Horizonte, ano 6, n. 25, p. 145-159, jul./set. 2006 
dade superar o argumento da falta de meios financeiros, deverá ser concedida a prestação. O funcionamento é uma ponderação de princípios e valores no caso concreto.

O Judiciário, nota Amaral, não decide a alocação de recursos abstratamente, nem controla as escolhas feitas pelos demais Poderes. "O Judiciário, ao apreciar demandas individuais ou coletivas relativas a pretensões positivas, deve ponderar o grau de essencialidade da pretensão, em função do mínimo existencial, e a excepcionalidade da situação, que possa justificar a decisão alocativa tomada pelo Estado que tenha resultado no não atendimento da pretensão." 25

Para não cair em extremos - acreditar que os direitos fundamentais são eficazes apenas nos termos da lei, ou crer que qualquer norma enseja o gozo de direito subjetivo individual —, o que seria insensato, para Sarlet, formula o professor sua tese, defendendo que somente o exame da hipótese em concreto determinará o quantum de aplicabilidade e eficácia é possível atribuir a um direito.

Também para Amaral, a postura de máxima eficácia das normas nega a cidadania ao levar o Estado à falência, frente à impossibilidade de cumprir simultaneamente todas as demandas. A postulação de uma prestação positiva está condicionada à existência de recursos públicos para sua realização. Frente à constatação de que certas demandas não podem ser simples atividade subsuntiva, o método hermenêutico clássico revela-se insuficiente nos casos que envolvem óbices metapositivos impostos aos direitos prestacionais.

\section{A ponderação de interesses}

Para harmonizar os elementos que incidem sobre a sindicabilidade dos direitos prestacionais, faz-se a ponderação. Sua inevitabilidade é, como atesta Gouvêa, garantia para Legislativo e Executivo "de que a apreciação dos aspectos políticos de seus atos não degenerará num puro e simples ativismo judicial." 26

Seguindo linha alemã, Andreas Krell entende que "os direitos sociais representam 'mandados de otimização' (Alexy) que devem ser 'densificados'; o seu cumprimento pode ser negado por parte do Estado somente

${ }^{24}$ AMARAL, 2001a, p. 216

${ }^{25}$ AMARAL, 2001a, p. 228.

A \& C R. de Dir. Administrativo e Constitucional, Belo Horizonte, ano 6, n. 25, p. 145-159, jul./set. 2006 
temporariamente em virtude de uma impossibilidade material evidente e comprovável." 27

O balanço dos interesses em jogo determinará o que o Judiciário pode oferecer. "O raciocínio ponderativo, que ainda busca parâmetros de maior objetividade, inclui a seleção das normas e dos fatos relevantes, com a atribuição de pesos aos diversos elementos em disputa, em um mecanismo de concessões recíprocas que procura preservar, na maior intensidade possível, os valores contrapostos." 28

O fio condutor do processo de ponderação é o princípio da razoabilidade. "De maneira geral, pode-se dizer que proporcionalidade e razoabilidade designam a exigência de que os atos da Administração e as leis, na consecução do interesse público, mobilizem de forma apropriada meios suficientes e necessários para o atingimento da finalidade." 29

A proporcionalidade é composta por subprincípios: a adequação, a necessidade e a proporcionalidade em sentido estrito. A adequação e a necessidade nortearão a conformação dos princípios aos elementos fáticos. Quanto aos elementos jurídicos, "É a proporcionalidade stricto sensu que regula o quanto se deve abrir mão de um determinado princípio para compô-lo com outro princípio ou regra. Através da ponderação, estabelece-se o quanto cada princípio cotejado terá de ser diluído em sua aplicação." 30

Qual a importância disso para a sindicabilidade dos direitos prestacionais? Consideremos situação em que a Administração demonstra que o reconhecimento de um direito prestacional restringirá consideravelmente o Erário público, comprometendo outras prestações também de interesse da coletividade. "A necessidade de alocação de recursos estatais na satisfação destes outros interesses funcionará como limite fático a ser observado quando do reconhecimento e da implementação do direito prestacional postulado na ação judicial, de tal forma que apenas a prestação em sua extensão necessária (e não mais do que isso) deverá ser prestigiada na decisão." ${ }^{11}$ A ponderação dará a extensão do direito postulado.

Conclui Gouvêa que "A proporcionalidade, no sentido a que se refere a teoria dos princípios, tem importância nas situações em que

\footnotetext{
${ }^{26}$ GOUVÊA, 2003, p. 142-143.

${ }^{27}$ KRELL, 2002, p. 59.

${ }^{28}$ BARCELLOS; BARROSO, 2003

${ }^{29}$ GOUVÊA, 2003, p. 133.

${ }^{30}$ GOUVÊA, 2003, p. 138-9.
}

A \& C R. de Dir. Administrativo e Constitucional, Belo Horizonte, ano 6, n. 25, p. 145-159, jul./set. 2006 
a existência ou a extensão do direito encontra-se questionada em face de fatores externos, sejam eles originariamente jurídicos ou fáticos." ${ }^{32}$

É notório que os recursos existem; o Estado deve, então, empregálos, sobretudo quando se refere a programas de baixo custo que atendem a padrões mínimos em matéria de direitos sociais. Porque não existe liberdade real se o indivíduo não tem acesso nem aos alimentos mínimos para uma vida saudável. Concorda Sarlet com a proteção ativa da vida, ainda que invocados o princípio da reserva do possível:

O mesmo raciocínio, assim, nos parece, poderá ser aplicado no que diz com outros direitos sociais prestacionais básicos, tais como educação, assistência social e para as condições materiais mínimas para uma existência digna. O princípio da dignidade da pessoa pode servir de parâmetro para avaliar qual o padrão mínimo em direitos sociais (mesmo como direitos subjetivos individuais) a ser reconhecido. ${ }^{33}$

Não podia ser outra a conclusão de Sarlet: nas situações em que os óbices habituais aos direitos sociais a prestações implicarem

[...] grave agressão (ou mesmo sacrifício) do valor maior da vida e da dignidade da pessoa humana, ou nas hipóteses em que, da análise dos bens constitucionais colidentes, resultar a prevalência do direito social prestacional, poder-seá sustentar, na esteira de Alexy e de Gomes Canotilho, que, na esfera de um padrão mínimo existencial, haverá, em princípio, a possibilidade de reconhecer um direito subjetivo definitivo a prestações, $[\ldots] .^{34}$

Gouvêa, analisando os estudos de Alexy, afirma que

No que concerne ao mínimo existencial, Alexy sequer admitiria a obstaculização em virtude dos óbices jurídicos da separação dos poderes e da competência orçamentária. Neste passo, Alexy, sem aderir a uma teoria absoluta do núcleo essencial dos direitos fundamentais, enxerga no mínimo existencial "condições nas quais pode dizer-se com muita segurança que não lhes precede nenhum princípio oposto". ${ }^{35}$

Aproveitando a esteira do mínimo existencial, Gouvêa enfatiza que os direitos que garantem a vida e a liberdade merecem "ser reconhecidos como prioritários, independentemente de juízo político dos órgãos in vestidos pelo voto popular." ${ }^{36}$ Barcellos afirma que, no tocante ao mínimo existencial, não há o que ponderar: ausente uma das condições essen-

31 GOUVÊA, 2003, p. 140.

32 GOUVÊA, 2003, p. 140.

33 SARLET, 2002, p. 185.

${ }^{34}$ SARLET, 2002, p. 185-186

A \& C R. de Dir. Administrativo e Constitucional, Belo Horizonte, ano 6, n. 25, p. 145-159, jul./set. 2006 
ciais à vida, a dignidade terá sido violada.

A teoria dos direitos fundamentais pode, desta feita, desempenhar diversos papéis argumentativos para a temática dos direitos prestacionais.

Havendo recursos limitados e diversos investimentos possíveis, deve-se conceder primazia àqueles relacionados à satisfação do mínimo existencial, [...]. Evidencia-se, neste passo, a circunstância de que os direitos fundamentais limitam a discricionariedade do administrador. A supremacia deontológica dos direitos fundamentais torna irrelevante qualquer juízo de conveniência, e sua urgência afasta a cognição da oportunidade..$^{37}$

\section{Bem escreve Ingo Sarlet:}

Não nos parece absurda a observação de que negar ao indivíduo os recursos materiais mínimos para manutenção de sua existência (negando-lhe, por exemplo, uma pensão adequada na velhice, quando já não possui condições de prover seu sustento) pode significar, em última análise, condená-lo à morte por inanição, por falta de atendimento médico, etc. Assim, há como sustentar — na esteira da doutrina dominante - que ao menos na esfera das condições existenciais mínimas encontramos um claro limite à liberdade de conformação do legislador. ${ }^{38}$

\section{Instrumental novo}

Noções como direito fundamental, mínimo existencial, reserva do possível, separação de poderes, e ponderação de interesses, fazem com que a interpretação e a aplicação do direito tenham nova dimensão, e o Judiciário, um novo papel. Barcellos e Barroso expõem o fruto da necessidade de novos instrumentais:

A nova interpretação constitucional assenta-se em um modelo de princípios, aplicáveis mediante ponderação, cabendo ao intérprete proceder à interação entre fato e norma e realizar as escolhas fundamentadas, dentro das possibilidades e limites oferecidos pelo sistema jurídico, visando à solução justa para o caso concreto. Nessa perspectiva pós-positivista do Direito, são idéias essenciais a normatividade dos princípios, a ponderação de valores e a teoria da argumentação. ${ }^{39}$

Os dois autores utilizam a denominação pós-positivismo para representar a tendência da consideração dos valores, da constatação da

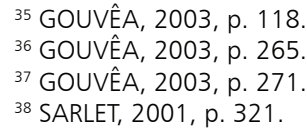

A \& C R. de Dir. Administrativo e Constitucional, Belo Horizonte, ano 6, n. 25, p. 145-159, jul./set. 2006 
natureza distinta dos princípios e das regras e da importância dos direitos fundamentais como núcleo do sistema jurídico. O avanço filosófico é aproveitado como instrumento técnico para o avanço do direito, para a mudança da realidade brasileira, marcada pela desigualdade.

O controle da legitimidade da solução resultante da ponderação tem sido feito por meio do exame da argumentação, considerando racionalmente se a solução proposta é a que melhor realiza o objetivo constitucional.

Gouvêa anuncia que a intersubjetividade revela-se um importante instrumento de controle da atuação judicial. O juiz procura julgar o caso da melhor forma possível porque há controle social e jurídico de sua decisão. A opinião pública e da comunidade jurídica, a literatura jurídica e as instâncias judiciárias superiores censurarão uma decisão mal formulada, o que significa proteção contra subjetivismos indesejáveis. Assim, ao julgar, o juiz preocupa-se com a aceitação intersubjetiva de sua tese, tornando-a a melhor possível. Jürgen Habermas foi quem formulou originariamente a teoria da razão comunicativa, na qual explica a aceitação intersubjetiva como critério de correção dos julgados. A motivação da decisão, nesse ponto, torna-se fundamental, pois pela exposição do raciocínio as partes controlarão a legitimidade e a validade da resposta jurisdicional.

\section{Conclusão}

Por questão de prioridade, responsabilidade e razoabilidade, interessa mais defender a dignidade do que o patrimônio. A reserva do possível abre os olhos para a prudência; todavia, não pode obstaculizar a efetivação de um direito essencial. Para concluir pela (in)exigibilidade de um direito, o Judiciário balanceará a essencialidade do direito e a justificativa do Estado para não prestá-lo. Se entender não haver razão para o Estado deixar de conceder o amparo, o Judiciário deve implementar o direito. Com essa atitude, o Judiciário não extrapola os limites de sua atuação nem fere o princípio da separação de poderes, porque esse princípio serve para garantir os cidadãos e seus direitos fundamentais contra abusos de poder, e o Judiciário é o grande controlador da atuação estatal. Concedendo a prestação para quem tem direito, atuando positivamente, os juízes realizam o Estado Social Democrático de Direito.

Clève finaliza o debate: "A reserva do possível não pode, num país

${ }^{39}$ BARCELLOS; BARROSO, 2003, p. 79.

A \& C R. de Dir. Administrativo e Constitucional, Belo Horizonte, ano 6, n. 25, p. 145-159, jul./set. 2006 
como o nosso, especialmente em relação ao mínimo existencial, ser compreendida como uma cláusula obstaculizadora, mas, antes, como uma cláusula que imponha cuidado, prudência e responsabilidade no campo da atividade judicial." 40

\section{Referências}

ALEXY, Robert. Direitos fundamentais no Estado constitucional democrático. Revista de Direito Administrativo, Rio de Janeiro, n. 217, 1999.

ALEXY, Robert. Teoría de los derechos fundamentales = Theorie der Grundrechte. Trad. Ernesto Valdés. Madrid: Centro de Estudios Constitucionales, 1997.

AMARAL, Gustavo. Direito, escassez Eं escolha: em busca de critérios jurídicos para lidar com a escassez de recursos e as decisões trágicas. Rio de Janeiro: Renovar, 2001a.

AMARAL, Gustavo. Interpretação dos direitos fundamentais e o conflito entre poderes. In: TORRES, Ricardo Lobo (Org.). Teoria dos direitos fundamentais. 2. ed. Rio de Janeiro: Renovar, 2001b.

BARCELLOS, Ana Paula de. A eficácia jurídica dos princípios constitucionais: o princípio da dignidade da pessoa humana. Rio de Janeiro: Renovar, 2002.

BARCELlOS, Ana Paula de; BARROSO, Luis Roberto. O começo da história: a nova interpretação constitucional e o papel dos princípios no direito brasileiro. Revista Interesse Público, Porto Alegre, v. 5, n. 19, p. 51-80, maio/jun. 2003.

BARROSO, Luis Roberto. O direito constitucional e a efetividade de suas normas: limites e possibilidades da Constituição Brasileira. 6. ed. Rio de Janeiro: Renovar, 2002.

CANOTILHO, José Joaquim Gomes; MOREIRA, Vital. Fundamentos da Constituição. Coimbra: Coimbra Ed., 1991.

CLÈVE, Clèmerson Merlin. A eficácia dos direitos fundamentais sociais. Boletim Científico da Escola Superior do Ministério Público da União, Brasília, ano 2, n. 8, p. 151-161, jul./set. 2003.

DOBROWOLSKI, Silvio. O Poder Judiciário e a Constituição. Revista Seqüência, Estudos Jurídicos e Políticos do Curso de Pós-Graduação em Direito da UFSC, n. 35, p. 31-40, 1998.

FALTA de controle prejudica investimentos sociais. Gazeta do Povo, Curitiba, Florianópolis, p. 17,25 jul. 2004.

FARIA, José Eduardo. Democracia e governabilidade: os direitos humanos à luz da globalização econômica. In: FARIA, José Eduardo (Org.). Direito e globalização econômica: implicações e perspectivas. São Paulo: Malheiros, 1998. p. 127-160.

GOUVÊA, Marcos Maselli. O controle judicial das omissões administrativas: novas perspectivas de implementação dos direitos prestacionais. Rio de Janeiro: Forense, 2003.

HESSE, Konrad. A força normativa da Constituição. Trad. Gilmar Ferreira Mendes. Porto Alegre: Sergio Antonio Fabris, 1991.

${ }^{40}$ CLÈVE, 2003, p. 160.

A \& C R. de Dir. Administrativo e Constitucional, Belo Horizonte, ano 6, n. 25, p. 145-159, jul./set. 2006 
KRELL, Andreas J. Direitos sociais e controle judicial no Brasil e na Alemanha: os (des)caminhos de um direito constitucional "comparado". Porto Alegre: Sergio Antonio Fabris, 2002.

MELLO, Celso Albuquerque de. O $\S 2^{\circ}$ do Art. $5^{\circ}$ da Constituição Federal. In: TORRES, Ricardo Lobo (Org.). Teoria dos direitos fundamentais. 2. ed. Rio de Janeiro: Renovar, 2001.

MORO, Sergio Fernando. Questões controvertidas sobre o benefício da assistência social. In: ROCHA, Daniel Machado da (Org.). Temas atuais de direito previdenciário e assistência social. Porto Alegre: Liv. do Advogado, 2003.

SARLET, Ingo Wolfgang. A eficácia dos direitos fundamentais. 2. ed. Porto Alegre: Liv. do Advogado, 2001.

SARLET, Ingo Wolfgang. O direito fundamental à moradia na Constituição: algumas anotações a respeito de seu contexto, conteúdo e possível eficácia. In: TORRES, Ricardo Lobo; MELLO, Celso de Albuquerque (Org.). Arquivos de direitos humanos. Rio de Janeiro: Renovar, 2002. v. 4, p. 137-191.

SARLET, Ingo Wolfgang. Os direitos fundamentais sociais na Constituição de 1988. Revista de Direito do Consumidor, São Paulo, n. 30, p. 96-124, abr./jun. 1999.

TORRES, Ricardo Lobo. A cidadania multifuncional da era dos direitos. In: (Org.). Teoria dos direitos fundamentais. 2. ed. Rio de Janeiro: Renovar, 2001a.

TORRES, Ricardo Lobo. O mínimo existencial e os direitos fundamentais. Revista de Direito Administrativo, Rio de Janeiro, n. 177, p. 29-49, jul./set. 1989.

TORRES, Ricardo Lobo. Teoria dos direitos fundamentais. 2. ed. Rio de Janeiro: Renovar, 2001b.

Informação bibliográfica deste texto, conforme a NBR 6023:2002 da Associação Brasileira de Normas Técnicas (ABNT):

HONÓRIO, Cláudia. O custo dos direitos prestacionais. A\&C Revista de Direito Administrativo e Constitucional, Belo Horizonte, ano 6, n. 25, p. 145-159, jul./set. 2006. 